\title{
Anti Psychotic Induced hyperprolactinaemia
}

\author{
Dawoodi Zainab Lokhandwala, De Sousa Avinash
}

\begin{abstract}
Hyperprolactinaemia has for decades been an inevitable and neglected side-effect of antipsychotic medication. The recent introduction of prolactin-sparing antipsychotic agents makes a re-examination of this problem timely. This article aims to review the literature on antipsychotic induced hyperprolactinaemia and its consequences. A literature search was made for key articles, supplemented by cross referencing. During antipsychotic treatment prolactin concentrations can rise to ten times normal levels or above and existing data indicate that a large number of female patients have amenorrhoea with or without galactorrhoea. Survey data, however, suggest that clinicians underestimate the prevalence of these conditions. Antipsychotic-induced hyperprolactinaemia should become a focus of interest in the drug treatment of psychiatric patients.
\end{abstract}

Key words : Antipsychotics, hyperprolactinemia, prolactin.

\section{Introduction}

Prolactin is a polypeptide hormone that exists as a number of isoforms and is involved in a number of physiological processes. Hyperprolactinemia is elevation of prolactin above the norm and can occur due to various causes including side effect of conventional and some second generation antipsychotics. Hyperprolactinemia has been shown to have many physiological consequences, some of them quite severe including sexual dysfunction, osteoporosis and behavioural effects (hostility, anxiety \& depression). ${ }^{1}$ Hyperprolactinemia is a disorder of the hypothalamo-pituitary-gonadal axis but may be seen as a side effect of typical and atypical antipsychotics as well. ${ }^{2}$ It has a prevalence of $0.4 \%$ in the general population and may be as high as $9-17 \%$ in the reproductive age group. The present paper reviews the physiology and pathology of hyperprolactinemia and management of antipsychotic induced hyperprolactinemia.

\section{The Neurophysiology of Prolactin}

Prolactin is a polypeptide hormone secreted by the lactotorph cells of anterior pituitary gland. Prolactin secretion shows circadian rhythm ${ }^{4}$, with highest levels occurring during the night and nadir occurring during the afternoon and evening. ${ }^{5}$ Normal basal levels of serum prolactin vary between 5 to $25 \mathrm{ng} / \mathrm{ml}$ in females and 5 to $15 \mathrm{ng} / \mathrm{ml}$ in males. ${ }^{6}$ Levels vary as per phase of menstrual cycle and can also vary according to age. The regulation of prolactin secretion is controlled by various endogenous agents that are released from or act through the hypothalamus via the hypothalamic pituitary portal vessels in response to various stimuli, including stress, sleep and suckling during breast feeding. Factors such as serotonin, estrogens and thyrotropin releasing hormone stimulate prolactin secretion, whereas gama amino butyric acid and acetylcholine inhibit secretion.

Most importantly, prolactin synthesis and secretion by pituitary lactotorph cells is tonically suppressed by hypothalamic dopamine traversing the portal venous system to impinge on lactotorph D2 receptors. ${ }^{6}$ Prolactin itself can cause dopamine release from hypothalamus and thus forms a negative feedback loop. Different isoforms of prolactin have different physiological functions and clinical effects. ${ }^{7}$ Apart from its well established function in stimulation and maintenance of lactation, prolactin has been found to be involved in over 300 separate functions including water and electrolyte imbalance, growth and development, reproduction, endocrinology and metabolism and immunoregulation. ${ }^{5}$ In terms of affecting brain and behaviour, prolactin is shown to increase brain neurogenesis in pregnant mice. Prolactin stimulates an increase in the number of neural progenitors in the forebrain which then migrate to the olfactory bulb. Here these additional neurons are thought to play a role in maternal behaviour because olfactory behaviour is critical for recognition and rearing of offspring. ${ }^{8}$ In humans, prolactin also plays a role in the regulation of sexual activity and behaviour. It has been observed that orgasms 
cause large and sustained (60 min) increase in plasma prolactin in both men and women9, which is associated with decreased sexual arousal and function. Furthermore, increased prolactin is thought to promote behaviours that encourage long-term partnership. ${ }^{10}$

\section{General aspects of Hyperprolactinaemia}

Hyperprolactinaemia is diagnosed when serum prolactin concentrations are greater than $20-25 \mathrm{ng} / \mathrm{ml}$ (400$500 \mathrm{mU} / 1)$ on two separate occasions. ${ }^{11}$ The Endocrine Society Clinical Practice guidelines (2011) state that in

order to establish the diagnosis of Hyperprolactinaemia, a single measurement of serum prolactin; at a level above the upper limit of normal confirms the diagnosis as long as the serum sample was obtained without excessive venipuncture stress. ${ }^{12}$ Dynamic tests of prolactin secretion using TRH, Ldopa, nomifensine, and domperidone are not superior to measuring a single serum prolactin sample for the diagnosis of Hyperprolactinaemia. ${ }^{13}$ A single determination is sufficient to establish the diagnosis, but when in doubt, sampling can be replaced on a different day at 15 to 20 min intervals to account for possible prolactin pulsatility. ${ }^{14}$

Hyperprolactinaemia most commonly results from a disorder of hypothalamic - pituitary axis ${ }^{15}$ and its causes can be grouped as physiological (sleep, sexual intercourse, pregnancy, nursing) and pathological (pituitary tumours most commonly prolactinomas, hypothyroidism and pharmacological). ${ }^{16}$ Traumatic childhood experiences such as parental separation or living with alcoholic father have been reported to produce increased predisposition to hyperprolactinemia. ${ }^{8}$ Medications that elevate prolactin levels include antipsychotics, oral contraceptive pills, oestrogens, tricyclic antidepressants, serotonergic drugs, propranolol, methyldopa and reserpine. ${ }^{8}$

\section{Antipsychotics and hyperprolactinemia}

Hyperprolactinema is thought to be caused by antipsychotic agents blocking the D2 receptors on the lactrotroph cells and their effects on the tubero-infundibular dopamine pathway, thus preventing inhibition of prolactin secretion. Furthermore it has been suggested that the degree of elevation of prolactin co relates with the degree of occupancy of D2 receptors in excess of $50 \%{ }^{17}$

\section{Traditional first generation antipsychotic drugs}

Most studies have shown that conventional anti psychotics are associated with a 2 to 10 fold increase in prolactin levels. ${ }^{17}$ The increase in prolactin that occurs due to use of conventional anti psychotics develops over the 1st week of treatment and remains elevated throughout the period of use. Once the treatment stops, the prolactin levels return to normal within 2-3 weeks. ${ }^{18}$ It has been suggested that tolerance can develop in patients treated chronically with anti-psychotics and that prolactin levels gradually decline with extended antipsychotic use.19 Prospective studies with an open or double-blind design have shown that medium-term treatment (3-9 weeks) with therapeutic dosages increases mean baseline prolactin levels up to ten-fold. ${ }^{20-22}$ Low daily dosing regimens (e.g. $200 \mathrm{mg}$ chlorpromazine) can cause significant prolactin elevations and levels have been reported to increase in a dose-dependent manner up to about $600 \mathrm{mg}$ chlorpromazine equivalents. ${ }^{23}$

\section{Second Generation Antipsychotic Drugs}

In general second generation anti psychotics produce lower increase in prolactin than conventional agents. ${ }^{24}$ Risperidone produces the most elevation in prolactin levels amongst the second generation agents. ${ }^{24}$ Olanzapine, Zotepine, Amisulpiride and Quetiapine are also associated with increase in prolactin levels. An analysis of double blind studies of risperidone in schizophrenic patients showed that there is dose dependent increase in prolactin concentrations in both men and women. ${ }^{25}$ In a randomised, double-blind, parallel group study that compared treatment with amisulpride $(1000 \mathrm{mg}$ daily) and oral flupentixol (25mg daily) in 32 men and women with schizophrenia who were free of oral antipsychotic medication for at least 4 weeks and depot neuroleptics for at least 3 months. After 4

weeks of treatment mean baseline prolactin levels were significantly elevated in both groups, in the amisulpride group by a factor of 10 and in the flupentixol group by a factor of 5. The difference between amisulpride and flupentixol treatment was significant in the women patients. ${ }^{26}$

Pooled data from two large, randomised, double-blind, controlled clinical trials comparing 8 weeks of treatment with fixed daily doses of risperidone $(1 \mathrm{mg}, 2 \mathrm{mg}, 4 \mathrm{mg}$, $6 \mathrm{mg}, 8 \mathrm{mg}, 10 \mathrm{mg}, 12 \mathrm{mg}$ and $16 \mathrm{mg}$ ), haloperidol (10mg and $20 \mathrm{mg}$ ) and placebo. Prolactin measurements were taken at end-point in 259 women. Levels in the risperidone group were increased above the normal range in proportion to the dose and their mean was significantly higher than in women treated with $10 \mathrm{mg}$ (but not $20 \mathrm{mg}$ ) of haloperidol.27 Whether risperidone has a greater effect on prolactin secretion than equivalent doses of haloperidol, as reported in a small 54-week continuation study, requires further analysis. ${ }^{28}$ 
In another study, researchers measured prolactin levels in 29 men and women with chronic schizophrenia after a 2week standardising therapy with oral fluphenazine $(20 \mathrm{mg}$ daily) and 6 weeks after switching to clozapine (mean dose $400 \mathrm{mg}$ daily) or risperidone (mean dose $6 \mathrm{mg}$ daily). At the end of fluphenazine treatment prolactin levels were increased by about twice the normal reference range in each group. After switching, levels decreased highly significantly into the normal reference range in the clozapine group, whereas they did not change significantly in the risperidone group. ${ }^{29}$ Preliminary evidence indicates that zotepine can also cause prolactin elevation in humans after both acute and chronic treatment.30 Studies of patients who are treatment naive or who have been withdrawn from treatment for a period of time indicate that schizophrenia per se does not affect prolactin concentrations. In such patients, prolactin concentrations are not

different from controls 31 although the circadian cycle in schizophrenic patients appears to be advanced by 1 to 1.5 hours, an advance that also occurs in patients on antipsychotics.

\section{Clinical manifestations of hyperprolactinemia}

Hyperprolactinemia may remain clinically asymptomatic. Women who suffered from hyperprolactinaemia consisting mainly of the trimeric form of prolactin (microprolactin) neither showed any clinical symptoms nor suffered from reproductive dysregulation, despite elevated prolactin concentrations $(700-1600 \mathrm{mg} / \mathrm{l}) .32 \mathrm{It}$ is thought that these polymeric forms of prolactin assays can be detected by current prolactin assays 33 , but they are not necessarily physiologically active. Clinical presentation may include hypogonadism, decreased libido and osteopenia in both sexes; infrequent or absent menstrual cycle, galactorrhoea and infertility in women. Low sperm count and reduced muscle mass in men.34 However, in addition to the effects of hyperprolactinaemia on sexual function and reproductive health, hyperprolactinaemia has been linked to other disorders as well.

While untreated schizophrenia patients exhibit decreased sexual desire 35, antipsychotic treatment is associated with restoration of sexual desire, yet it entails erectile, orgasmic and sexual satisfaction problems.36 In women receiving antipsychotics, the incidence of menstrual disturbances is 15 to $50 \%$ There may be infrequent or absent menstrual cycles.37 The feedback loop that links prolactin and dopamine also affects the release of gonadotropin releasing hormone $(\mathrm{GnRH})$, which like prolactin, is inhibited by dopamine. When the inhibitory effect of dopamine on prolactin is lost (as in treatment with dopamine antagonist), hyperprolactinemia occurs. This rise in prolactin levels causes a concomitant rise in

dopamine levels which in turn inhibits the release of GnRH . The lower levels of GnRH lead to the symptoms of hypogonadism that are a primary consequence of hyperprolactinemia. ${ }^{38}$ The association between hyperprolactinemia and osteoporosis appears to be mediated by oestrogen deficiency secondary to sustained prolactin elevation, although prolactin itself may have a direct effect on bone formation. ${ }^{39}$ Some studies state that bone loss occurs secondary to hyperprolactinemia mediated sex steroid attenuation. Spinal bone density is decreased by approximately $25 \%$ in women with hyperprolactinemia ${ }^{40}$ and is not necessarily restored with normalization of prolactin levels. Several studies have linked hyperprolactinemia to an increase in risk of breast cancer in women. The possible mechanisms include increase in synthesis and expression of prolactin receptors in malignant breast tissue and a prolactin-induced increase in DNA synthesis in breast cancer cells in vivo. ${ }^{41}$

\section{Managing antipsychotic induced hyperprolactinemia}

When treating antipsychotic induced hyperprolactinemia, decisions should be made on an individual basis after a full and frank discussion with the patient. These discussions should include consideration of benefits of antipsychotic therapy as well as potential impact of any adverse effects. The importance of discussing symptom impact is highlighted by data showing that only a minority of patients discontinue their antipsychotic medication because of breast tenderness, galactorrhoea or menstrual irregularities. 42

The Endocrine society Clinical practice guidelines, 2011 state that no treatment is necessary in an asymptomatic patient with drug induced hyperprolactinemia.43 Increase in prolactin could be due to formation of macroprolactin which does not have serious consequences for the patient. If there

are doubts about the cause of hyperprolactinemia, other possible causes especially tumours must be excluded.44 Sexual side effects are the commonest cause for non compliance. The decision to change the current antipsychotic to an agent with lower dopamine antagonist property or aripiprazole (an atypical antipsychotic with both Dopamine agonist and antagonist activity that can lower prolactin and reverse hyperprolactinemia side effects) should be made on the basis of risk benefit estimation. 45 
Adjunctive therapies have also been tested to reduce the symptoms of hyperprolactinemia, but these are associated with their own risks. Oestrogen replacement can prevent the effects of oestrogen deficiency, hypogonadal symptoms, but it carries the risk of thromboembolism. ${ }^{46}$ Dopamine agonists such as Cabergoline and Bromocriptine have been suggested for the management of hyperprolactinemia in patients receiving antipsychotics, but these are associated with side effects and may worsen psychosis. 47

\section{Conclusions}

Endocrine symptoms occur in a large proportion of women treated with prolactin elevating antipsychotic drugs. These symptoms can cause significant distress and may affect compliance with medication. A significant proportion of premenopausal women with psychotic disorders may be at risk of premature bone loss and other consequences of chronic hypooestrogenism due to longterm antipsychotic medication. The presence of menstrual irregularities, breast symptoms and sexual dysfunction should be assessed before and during treatment with prolactin-elevating drugs and management options should be discussed with the patient. Thus management of antipsychotic hyperprolactinemia should exclude all

other causes, involve a regular monitoring of adverse effects and include a regular risk benefit discussion with the patient.

\section{References}

1. Halbreich U, Kinon BJ, Gilmore JA ,Kahn LS. Elevated prolactin levels in patients with Schizophrenia: mechanisms and related adverse effects. Psychoneuroendocrinology 2003;suppl 1:53-67.

2. Weick A, Haddad PM. Antipsychotic-induced hyperprolactinaemia in women : pathophysiology, severity and consequences : Selective literature review. Br J Psychiatry 2003;182:199-204.

3. Rao ML, Gross G, Strebel B, Halaris A, Huber G, Braunig P, Marler M. Circadian rhythm of tryptophan, serotonin, melatonin and pituitary hormones in schizophrenia. Biol Psychiatry 1994;35:151-63.

4. Hamner M .The effects of atypical antipsychotics on serum prolactin levels. Ann Clin Psychiatry 2002;14:163-73.

5. Ragson NL, Hendrick VC, Garrick T. Endocrine and metabolic disorders. In Kaplan and Saddock's Comprehensive textbook of Psychiatry, 9th edition, pg 2303-14.
6. Sinha YN. Structural variants of prolactin: occurrence and physiological significance. Endocrine Rev 1995;16:354-69.

7. Shingo T, Gregg C, Enwere E, et al. Pregnancystimulated neurogenesis in the adult female forebrain mediated by prolactin. Science 2003;299:117-20.

8. Exton MS, Kruger TH, Koch M, Paulson E, Knapp W, Hartmann U, Schedlowski M. Coitus induced orgasm stimulates prolactin secretion in healthy subjects. Psychoneuroendocrinology 2001;26:287-94.

9. Kruger TH, Haake P, Hartmann U, Schedlowski M, Exton MS. Orgasm induced prolactin secretion: feedback control of sexual drive. Neurosci Behav Rev 2002;26:31-44.

10. Luciano AA. Clinical presentation of Hyperprolactinaemia. J Reprod Med 1999;44:1085-90.

11. Mansini T, Casaneuva FF, Guistina A. Hyperprolactinemia and Prolactinomas. Endocr Metab Clin NAm 2008;37:67-99.

12. Casanueva FF, Molitch ME, Schlechte JA, Abs R, Bonert V. Guidelines of the Pituitary Society for the diagnosis and management of prolactinomas. Clin Endocrinol 2006;65:265-273.

13. Mancini T, Casabueva FF, Giustina A. Hyperprolactinaemia and prolactinomas. Endocrinol Rev 2009;31:167-80.

14. Petty RG. Prolactin and antipsychotic medications: mechanism of action. Schizophr Res 1999;35(Suppl):S67-73.

15. Mah PM, Webster J. Hyperprolactinema: etiology, diagnosis, and management. Semin Reprod Med 2002;20:365-73.

16. Nordstrom AL, Farde L. Plasma prolactinand central D2 receptor occupancy in antipsychotic drug treated patients. J Clin Psychopharmacol 1998;18:305-10.

17. Meltzer HY, Fang VS. The effect of neuroleptics on serum prolactin in schizophrenic patients. Arch Gen Psychiatry 1976;33:279-86.

18. Gruen PH, Sachar EJ, Langer G, Altman N, Leifer M, Frantz A, Halpern FS. Prolactin responces to neuroleptics in normal and schizophrenic subjects. Arch Gen Psychiatry 1978;35:108-16. 
19. Kuruvilla A, Peedicayil J, Srikrishna G, et al. A study of serumprolactin levels in schizophrenia: comparison of males and females. Clin Exp Pharmacol Physiol 1992;19:603-6.

20. Arvanitis LA, Miller BG and Seroquel Trial 13 Study Group. Multiple fixed doses of 'Seroquel' (quetiapine) in patients with acute exacerbations of schizophrenia: a comparisonwith haloperidol and placebo. Biol Psychiatry 1997;42:233-46.

21. Crawford AM, Beasley CM, Tollefson GD. The acute and long-term effects of olanzapine compared with placebo and haloperidol on serum prolactin concentrations. Schizophr Res 1997;26:41-54.

22. Green AL, Brown WA. Prolactin and neuroleptic drugs. Endocrinol Metab Clin N Am 1988;17:21323.

23. Turkington RW, Prolactin secretion in patients treated with various drugs: phenothiazines, tricyclic antidepressants, reserpine, and methyldopa. Arch Intern Med 1972;130:349-54.

24. Marken PA, Haykal RF, Fisher JN. Management of psychotropic induced hyperprolactinemia. Clin Pharm 1992;11:851-6.

25. Gruender G, Wetzel H, Schloesser R. et al. Neuroendocrine response to antipsychotics: effects of drug type and gender. Biol Psychiatry 1999;45: 89-97.

26. Kleinberg DL, Davis JM, De Coster R, et al. Prolactin levels and adverse effects in patients treated with risperidone. J Clin Psychopharmacol 1999;19: 57-61.

27. David SR, Taylor CC, Kinon BJ, et al. The effects of olanzapine, risperidone, and haloperidol on plasma prolactin levels in patients with schizophrenia. Clin Ther 2000;22:1085-96.

28. Breier AF, Malhotra AK, Tung-Ping S, et al. Clozapine and risperidone in chronic schizophrenia: effects on symptoms, parkinsonian side effects and neuroendocrine response. Am J Psychiatry 1999;156:294-8.

29. Goodnick PJ, Rodriguez L, Santana O. Antipsychotics: impact on prolactin levels. Exp Opin Clin Pharmacother 2002;3:1381-91.

30. Brown WA, Laughren TP. Tolerance to the prolactin elevated effect of neuroleptics. Psychiatry Res 1981;5:317-22.
31. Igarashi $Y$, Higuchi $T$, Toyoshima R, Noguchi T, Moroji T. Tolerance to prolactin secretion in the long-term treatment with neuroleptics in schizophrenia. Adv Biochem Psychopharmacol 1985;40:95-8.

32. Goodnick PJ, Rodriguez L, Santana O. Antipsychotics: impact on prolactin levels. Expert Opin Pharmacother 2002;3:1381-91.

33. Klienberg DL, Davis JM, de Coster R, Van Baelen B, Brecher M. Prolactin levels and adverse events in patients treated with resperidone. J Clin Psychopharmacol 1999;19:57-61.

34. Brambilla F, Gaustalla A, Guerrini A. Prolactin secretion in chronic schizophrenia. Acta Psychiatr Scand 1976;54:275-86.

35. Hattori N. The frequency of macroprolactinemia in pregnant women and the heterogeneity of its etiologies. J Clin Endocrinol Metab 1996;81:586-90.

36. Diver MJ, Ewins DL, Worth RC, Bowles S. An unusual form of big, big (macro) prolactin in a pregnant patient. Clin Chem 2001;47:346-8.

37. Biller BM, Luciano A, Crosignani PG, et al. Guidelines for the diagnosis and treatment of hyperprolactinemia. J Reprod Med 1999;44:1075-84.

38. Aizenberg D, Zemishlany Z, Dorfman-Ertog P, et al. Sexual dysfunction in male schizophrenic patients. J Clin Psychiatry 1995;56:137-41.

39. Knegtering $\mathrm{H}$, van der Moolen AE, Castelein $\mathrm{S}$ et al. What are the effects of antipsychotics on sexual dysfunctions and endocrine functioning? Psychoneuroendocrinology 2003;28(Suppl 2):109-23.

40. Compton MT, Miller AH. Antipsychotic induced hyperprolactinemia and sexual dysfunction. Psychopharmacol Bull 2002;36:143-64.

41. Beumont PJ, Gelder MG, Friesen GH, Harris GW et al. The effects of phenothiazines on endocrine function: I. Patients with inappropriate lactation and amenorrhoea. Br J Psychiatry 1974;124:41319.

42. Rosen CJ, Kessenich CR. The pathophysiology and the treatment of postmenopausal osteoporosis. An evidence-based approach to estrogens replacement therapy. Endocrinol Metab Clin North Am 1997;26:295-311. 
43. Schlechte J, el-Khoury G, Kathol M, Walkner L. Forearm and vertebral bone mineral in treated and untreated hyperprolactinemic amenorrhea. J Clin Endocrinol Metab 1987;64;1021-26.

44. Hankinson SE, Willett WC, Michaud DS, Manson $\mathrm{JE}$, et al. Plasma prolactin levels and subsequent risk of breast cancer in postmenopausal women. J Natl Cancer Inst 1999;91:629-34.

45. Casey DE. Side effect profiles of new antipsychotic agents. J Clin Psychiatry. 1996;57 Suppl 11:40-5.

46. Peverill RE. Hormone therapy and venous thromboembolism. Baillieres Best Pract Res Clin Endocrinol Metab 2003;17:149-64.

47. Cohen LG, Biederman J. Treatment of risperidoneinduced hyperprolactinemia with a dopamine agonist in children. J Child Adolesc Psychopharmacol 2001;11:435-40.

\section{Authors:}

1. Dr. Zainab Lokhandwala Dawoodi

Consultant Psychiatrist

Private Practice - Pune

2 Dr. Avinash De Sousa

Consultant Psychiatrist - Mumbai

Address for correspondence -

Dr. Avinash De Sousa

Carmel, 18 St. Francis Avenue, Off S.V. Road,

Santacruz West, Mumbai-54.

Tel - 022-26460002

E-mail-avinashdes999@yahoo.co.uk

Conflict of Interest - Nil

Financial Disclosures - Nil

Sources of Support - Nil

Acknowledgements - Nil 